\title{
Music therapy intervention in cardiac autonomic modulation, anxiety, and depression in mothers of preterms: randomized controlled trial
}

Mayara K. A. Ribeiro ${ }^{1 *}$ (D), Tereza R. M. Alcântara-Silva², Jordana C. M. Oliveira', Tamara C. Paula', João B. R. Dutra ${ }^{3}$, Gustavo R. Pedrino ${ }^{3}$, Karina Simões ${ }^{4}$, Romes B. Sousa ${ }^{3}$ and Ana C. S. Rebelo ${ }^{1,4}$

\begin{abstract}
Background: Mothers of preterm infants often have symptoms of anxiety and depression, recognized as risk factors for the development of cardiovascular diseases and associated with low rates of heart rate variability (HRV). This study aimed to evaluate the influence of music therapy intervention on the autonomic control of heart rate, anxiety, and depression in mothers.

Methods: Prospective randomized clinical trial including 21 mothers of preterms admitted to the Neonatal Intensive Care Unit of a tertiary hospital, recruited from August 2015 to September 2017, and divided into control group (CG; $n$ $=11$ ) and music therapy group (MTG; $n=10$ ). Participants underwent anxiety and depression evaluation, as well as measurements of the intervals between consecutive heartbeats or RR intervals for the analysis of HRV at the first and the last weeks of hospitalization of their preterms. Music therapy sessions lasting 30-45 min were individually delivered weekly using receptive techniques. The mean and standard deviation of variables were obtained and the normality of data was analyzed using the Kolmogorov-Smirnov test. The paired sample t-test or Wilcoxon test were employed to calculate the differences between variables before and after music therapy intervention. The correlations anxiety versus heart variables and depression versus heart variables were established using Spearman correlation test. Fisher's exact test was used to verify the differences between categorical variables. A significance level of $p<0.05$ was established. Statistical analysis were performed using the Statistical Package for the Social Sciences, version 20.
\end{abstract}

Results: Participants in MTG had an average of seven sessions of music therapy, and showed improvement in anxiety and depression scores and autonomic indexes of the time domain $(p<0.05)$. Significant correlations were found between depression and parasympathetic modulation using linear $(r=-0.687 ; p=0.028)$ and nonlinear analyses $(r=-0$. 689; $p=0.027)$ in MTG.

Conclusion: Music therapy had a significant and positive impact on anxiety and depression, acting on prevention of cardiovascular diseases, major threats to modern society.

Trial registration: Brazilian Registry of Clinical Trials (no. RBR-3x7gz8). Retrospectively registered on November 17, 2017.

Keywords: Heart rate variability, Anxiety, Depression, Mothers, Music therapy

\footnotetext{
* Correspondence: mayara.ribeiromt@gmail.com

'School of Medicine, Universidade Federal de Goiás, Goiânia, GO, Brazil

Full list of author information is available at the end of the article
}

(c) The Author(s). 2018 Open Access This article is distributed under the terms of the Creative Commons Attribution 4.0 International License (http://creativecommons.org/licenses/by/4.0/), which permits unrestricted use, distribution, and reproduction in any medium, provided you give appropriate credit to the original author(s) and the source, provide a link to the Creative Commons license, and indicate if changes were made. The Creative Commons Public Domain Dedication waiver (http://creativecommons.org/publicdomain/zero/1.0/) applies to the data made available in this article, unless otherwise stated. 


\section{Background}

Hospitalization of preterm infants in a Neonatal Intensive Care Unit (NICU) can be a time of great suffering for both the family and the patient. Under these circumstances, parents, especially mothers, may experience a number of reactions, including sadness, fear, disappointment, anger, and helplessness [1]. Parents should be encouraged to express any feelings of guilt, anxiety, inadequacy, or anger and also ask for help and/or support. This way, they may be able to better cope with these negative emotions and to understand that these are normal reactions experienced by most parents who face this situation [2].

Anxiety and depression are recognized as significant risk factors for the development of cardiovascular diseases $[3,4]$, and therefore can compromise the health and well-being of individuals affected by them. They have also been associated with changes in cardiovascular modulation and sympathovagal balance measured by heart rate variability (HRV) indices [5]. Overall, HRV describes oscillations in the intervals between consecutive heartbeats ( $R R$ intervals) caused by the influences of the autonomic nervous system (ANS) on the sinus node [6, 7]. Among several methods used to evaluate autonomic modulation, HRV has emerged as a simple, noninvasive measurement technique and has been considered one of the most promising markers of autonomic balance [8].

Taking these risks into consideration, it is important to propose strategies to minimize the symptoms of anxiety and depression. One of the strategies is music therapy, defined by the American Music Therapy Association as the clinical and evidence-based use of musical interventions to meet individualized goals within a therapeutic relationship by an accredited professional who has completed an approved music therapy program [9].

Music therapy interventions, performed with the use of receptive techniques, have been proven to significantly reduce anxiety levels [10]. During kangaroo care, music therapy intervention using the harp had a significant effect to minimize the level of anxiety of motherbaby dyads compared to the control group in a randomized study [11]. Another randomized study with mothers and their infants in a NICU showed that: a) the group in which maternal singing was associated with kangaroo care had a significant reduction in maternal anxiety levels compared to that under kangaroo care without music intervention; b) the preterms exhibited better autonomic stability, with significant change in low frequency (LF) and high frequency (HF) and lower LF/ HF ratio, during kangaroo care in association with maternal singing, both during the intervention and recovery phases, compared to those under kangaroo care without music intervention and baseline $(p=-0.05)$ [12].
Studies that evaluate the benefits of music therapy for mothers of preterm infants are still scarce [13], and so are those correlating anxiety and depression with cardiovascular autonomic dysfunction assessed by HRV. Therefore, the present study aimed to evaluate the influence of music therapy intervention on the autonomic control of heart rate, anxiety, and depression in mothers of preterm infants admitted to the NICU. We hypothesized that music therapy is able to reduce the symptoms of anxiety and depression as well as increase HRV in mothers of preterm infants in the NICU.

\section{Methods}

This is a prospective randomized clinical trial that included mothers of preterm infants admitted to the NICU of the Women's Hospital and Maternity Dona Iris (WHMDI), a tertiary hospital in Goiânia, GO, Brazil, recruited from August 2015 to September 2017. The research project was approved by the WHMDI Academic Board and the Ethics and Research Committee of the Universidade Federal de Goiás (no. 636368). It was registered in the Brazilian Registry of Clinical Trials (no. RBR-3x7gz8) and complies with the principles of the Committee on Publication Ethics.

\section{Inclusion and exclusion criteria}

Mothers (18-40 years old) of preterm infants admitted to the NICU of the WHMDI with prediction of at least one-month hospitalization were included. Exclusion criteria were cognitive alteration and/or auditory deficiency that prevented comprehension of the evaluations and questionnaires involved, uncontrolled systemic diseases, use of beta-blockers or antidepressants, and continued use of illicit drugs and/or alcohol during pregnancy and postpartum.

\section{Randomization}

The determination of the number of volunteer participants was based on a pilot study conducted by our research group. The mean and standard deviation (SD) of root mean square of successive differences between adjacent RR intervals (RMSSD) were calculated. This is a parameter to evaluate parasympathetic modulation, employed in this calculation since it is considered appropriate to cross anxiety and depression data. Sample calculation was carried out using the GPower 3.1.9.2 application for the $95 \%$ confidence interval, study power of $80 \%$, and Effect Size d 0.89 . Therefore, the sample size was determined as 36 individuals (24 participants in music therapy group - MTG; 12 participants in control group - CG). Considering a possible sample loss during the study, 46 participants were recruited in the first week of admission of their preterms in the NICU and their informed consent was obtained. To carry out 
simple randomization, $50 \mathrm{kraft}$ sealed envelopes containing the names of the groups (CG and MTG) in identical proportions were used to assign participants to each group. The randomized envelope was opened by the participant or by the researcher within her line of sight, resulting in: 21 participants in CG and 25 participants in MTG. Due to the deadline of the funding institution, it was not possible to randomize 50 participants.

\section{Evaluation}

To evaluate anxiety, depression, and HRV, all the participants responded to the validated Brazilian Portuguese versions of the Beck Anxiety Inventory (BAI) and Beck Depression Inventory (BDI) [14], and RR intervals were recorded for the analysis of HRV, respectively, at two different moments, the first and the last weeks of hospitalization of their preterms. Once the preterm was scheduled to be discharged by the medical staff, the mother underwent the final evaluations. In addition, participants responded to a sociodemographic questionnaire.

\section{Beck scales}

BAI and BDI are 21-item self-report inventories designed to measure the intensity of anxiety and depression, respectively, by assessing symptoms commonly associated with these conditions. A psychologist applied BAI and BDI orally and the participants responded using a 4-point Likert scale, ranging from 0 to $3(0=$ not at all bothered; $3=$ severely bothered), to express how bothered they felt by each symptom during the past week. The total scores for both scales range from 0 to 63 points. For BDI, total scores indicate that depression is minimal (from 0 to 11 points), mild (from 12 to 19 points), moderate (from 20 to 35 points), or severe (from 36 to 63 points). For BAI, the cut-off points indicate that anxiety is minimal (from 0 to 10 points), mild (from 11 to 19 points), moderate (from 20 to 30 points), or severe (from 31 to 63 points) [14].

\section{RR intervals recording and HRV analysis}

All participants were evaluated in the afternoon to avoid different physiological responses due to circadian changes. The measurements were carried out in an airconditioned room, at temperatures ranging from $22^{\circ} \mathrm{C}$ to $24{ }^{\circ} \mathrm{C}$ and relative humidity between 40 and $60 \%$. Each participant was previously instructed: not to ingest stimulant beverages such as caffeine or alcohol the night before and on the day of testing; not to perform moderate or intense exercises the day before the measurements; to avoid copious meals; and to have a light meal at least $2 \mathrm{~h}$ before testing.

$\mathrm{RR}$ intervals were recorded at rest, while the participants were seated and breathing normally, over a 12-min period, using a cardiofrequencimeter (Polar ${ }^{\circ}$ V800, Polar Electro Oy, Kempele, Finland). It is worth emphasizing that, in many studies involving music, RR intervals are recorded during music listening, which was not the procedure adopted in the present study. In both the initial and final evaluations of participants in CG and MTG, RR intervals were recorded in silence. And for the final evaluation of participants in MTG, it was analyzed at least $12 \mathrm{~h}$ after the last music therapy session. This approach intended to verify the prolonged effects of the music therapy intervention in MTG.

HRV was analyzed using linear (time and frequency domains) and nonlinear methods. The region presenting the greatest stability in the RR interval time series with 256 consecutive beats was selected for the analyses. Artifacts in the RR interval time series were corrected by deletion, interpolation, and using Kubios HRV [15]. Time domain parameters studied were the standard deviation of $\mathrm{NN}$ intervals (interbeat intervals from which artifacts have been removed; SDNN) and RMSSD. SDNN reflects overall HRV, whereas RMSSD is an index of cardiac parasympathetic modulation. For frequency domain parameters, spectral analysis was carried out using fast Fourier transform, applied to a single window, after a linear trend subtraction in previously chosen RR intervals. The spectral components were obtained at LF $(0.04-0.15 \mathrm{~Hz})$ and HF $(0.15-0.4 \mathrm{~Hz})$, in absolute units $\left(\mathrm{ms}^{2}\right)$, and the normalized units were computed by dividing the absolute power of a given LF or HF component $\left(\mathrm{ms}^{2}\right)$ by the total power, subtracting the very low frequency (VLF: $0.003-0.04 \mathrm{~Hz}$ ) power, and multiplying this ratio by 100 . Since the LF band is modulated by both the sympathetic and the parasympathetic nervous systems and the HF band is correlated with vagal cardiac control, the LF/HF ratio was calculated to determine the sympathovagal balance. The VLF band of 0.003 to 0.04 $\mathrm{Hz}$ represents the actions of humoral, vasomotor, and temperature regulation in addition to the activity of the renin-angiotensin-aldosterone system [16].

Nonlinear indices representing parasympathetic modulation and overall HRV variability were instantaneous beat-to-beat variability (SD1) and continuous beatto-beat variability (SD2), with approximate entropy and sample entropy representing HRV complexity [17].

\section{Music therapy intervention}

A music therapy questionnaire [18] was applied to participants in MTG to collect data on their experience with music and a list of favorite songs. Music therapy intervention began after the conclusion of the initial evaluation stage. The sessions, conducted by professional music therapists, were held once a week, individually, and lasted from 30 to $45 \mathrm{~min}$. The number of sessions differed among participants, since they remained in 
music therapy for the period of hospitalization of their preterm infants in the NICU, which varied according to their clinical situation.

Each music therapy session consisted of the following steps [18]:

1. Reception: meeting the participant in the NICU or her room and taking her to the office for care;

2. Type I music listening: listening to an instrumental piece, for 2 to $4 \mathrm{~min}$, aiming to provide the participant with a moment for quiet reflection to think of her life and the hospitalization of her preterm in the NICU. Instrumental music was chosen to avoid the influence of lyrics on the musical perception of the participant, considering possible associations with a past event, positive or negative. The selection of type I pieces followed these criteria: a) classical music; b) baroque, classical, or romantic periods; c) tonal; d) with regular pulse; e) containing few points of tension, followed by tension resolution; f) with low levels of dissonance. Predictability, generated mainly by regular pulse, harmonic cadence following a tonal axis, and resolutive endings are important features to provide the listener with a sense of security. Instrumental pieces, usually solos or duets, in slow tempo [60 to 80 beats per minute (bpm)] [19], with clearly delineated musical phrases were chosen for this phase. The same pieces were used in the same sequence for all participants in MTG;

3. Therapeutic music listening: nomenclature proposed by Alcântara-Silva [18] aiming to establish some differences in relation to music listening "in therapy" or "in medicine". It differs from other studies because the present technique is inserted in the therapeutic context in a processual manner, while in other studies the musical intervention often happens in a single moment [18]. The musical repertoire used in therapeutic music listening consisted of songs selected by the participant, unlike most other studies, in which the researcher selects them;

4. Verbal processing: a moment for the participant to freely share her experience of therapeutic music listening. The purpose of this procedure is to help participants use musical expression to find their own coping strategies, so that they can be strengthened to face moments of anguish and fragility;

5. Type II music listening: the selection of type II pieces followed the same criteria described for type I selection $(a-f)$. However, in this phase the repertoire consisted mainly of densely textured pieces, composed for orchestras, with various timbres, progressing faster than type I pieces (above $80 \mathrm{bpm}$ ). All pieces were instrumental, except for the last one, which was vocal. The same pieces were used in the same sequence for all participants in MTG;

6. Conclusion: the music therapist briefly commented the issues approached during that session, set up the date for the following one, and concluded the session.

\section{Statistical analysis}

The mean and SD of each variable were calculated. The normality of data was analyzed using the KolmogorovSmirnov test. The differences between the variables evaluated before and after music therapy intervention were calculated using paired sample t-test or Wilcoxon test. The correlations between anxiety and heart variables and between depression and heart variables were established using Spearman correlation test. The differences between categorical variables were calculated using Fisher's exact test. Effect size measures were calculated dividing the mean difference by its SD at two different moments, the first and the last weeks of hospitalization of the preterms. The magnitude of the effect size was categorized following these criteria: $0.2<\mathrm{d}<0.5=$ small; $0.5<\mathrm{d}<0.8=$ medium; and $\mathrm{d}>0.8=$ large [20]. A significance level of $p<0.05$ was established. Statistical analyses were performed using the Statistical Package for Social Sciences, version 20 (Chicago, IL, United States).

\section{Results}

Between August 2015 and September 2017, 46 mothers were recruited and randomly assigned to CG or MTG, as shown in the CONSORT diagram (Fig. 1). In spite of the high number of participants enrolled, data collection was completed for 21 mothers (CG: 11; MTG: 10), not reaching the sample size determined for the study.

Several reasons interfered in the participation of the mothers in this study: a) some babies were discharged before the due date, and because the mothers did not live in the city where the study was performed, they missed the music therapy sessions and/or the final evaluation; b) some mothers had difficulty in staying at the hospital to follow their babies and missed the music therapy sessions and/or the final evaluation; c) non-completion of $75 \%$ of music therapy sessions for participants in MTG; d) death of infants (four mothers that participated in MTG lost their babies during the study; although they were offered music therapy support to cope with their grief and mourning, their participation was not included in the statistical analysis to avoid bias); e) withdrawal for personal reasons; f) error in the final HRV test, preventing comparison between the first and the last results. 


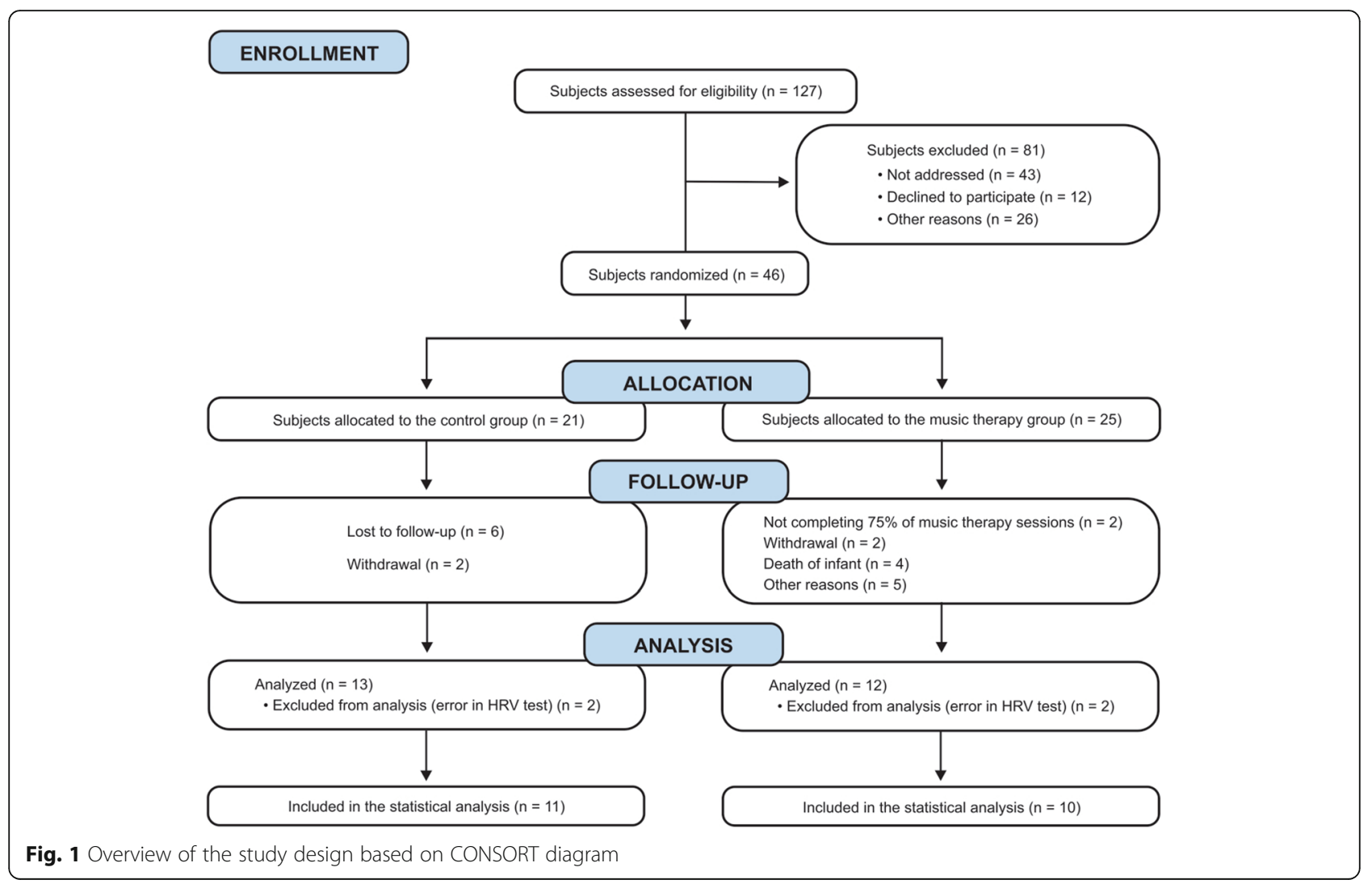

The sociodemographic profile of the participants is summarized in Table 1. The mean age of the participants at the beginning of the study was $25.8 \pm 4.5$ years in MTG and 26.2 \pm 7.1 years in CG, showing that the sample was homogeneous $(p=0.4198)$. The mean age at first pregnancy was $20.5 \pm 3.5$ years in MTG and $24.4 \pm 7.8$ years in CG.

The mothers allocated to MTG had an average of $7 \pm$ 2 music therapy sessions. The psychological variables anxiety and depression, analyzed using t-test, exhibited significant improvement in MTG, but not in CG (Table 2). They were also investigated using Fisher's exact test (Table 3) [14], and a migration from higher to lower levels of anxiety and depression was observed in both groups, comparing the outcomes in the initial and final evaluations. However, significant improvement was registered in MTG only for anxiety.

Comparisons between the groups showed that time domain parameters (SDNN, RMSSD, and pNN50) and nonlinear dynamics (SD1 index) presented a lower mean value in MTG compared to CG in the initial evaluation. This scenario reversed after the music therapy intervention, and a significant increase in these parameters was found for participants in MTG, who had higher values than those observed for the participants in CG (Table 2). No significant changes in frequency domain parameters were registered for either group.
After the music therapy sessions, significant correlations were found between BDI and RMSSD $(r=-0.687$; $p=0.028)$ and SD1 $(r=-0.689 ; p=0.027)$ for participants in MTG, using Spearman correlation test, demonstrating an inversely proportional correlation between HRV and the clinical symptomatology of depression (Fig. 2). Despite this trend, no correlations were observed between BAI scores and psychophysiological variables based on HRV analysis.

\section{Discussion}

It is already well known that music therapy decreases the levels of anxiety and depression in different clinical contexts $[3,21,22]$. Nonetheless, studies including preterm mothers have predominantly addressed the beneficial effects of music therapy only on anxiety scores, not approaching depression scores $[11,23]$.

In this study, therapeutic music listening was adopted as the therapeutic procedure, i.e. the participants listened to familiar songs selected by themselves, and the sessions took place once a week individually with each mother, without the presence of the preterm, to offer specific therapeutic support to her needs. Familiar songs can help control anxiety, improve concentration, recover memories, provide a sense of security and motivation, and stimulate social interaction, simultaneously giving people the opportunity to recognize and improve their 
Table 1 Sociodemographic profile of the participants in this study

\begin{tabular}{|c|c|c|c|}
\hline $\begin{array}{l}\text { Sociodemographic } \\
\text { feature }\end{array}$ & & $\begin{array}{l}\text { Music therapy } \\
\text { group } \mathrm{n}(\%)\end{array}$ & $\begin{array}{l}\text { Control } \\
\text { group n (\%) }\end{array}$ \\
\hline \multirow[t]{4}{*}{ Age band (years) } & $18-23$ & $3(30)$ & $4(36.4)$ \\
\hline & $24-29$ & $3(30)$ & $4(36.4)$ \\
\hline & $30-35$ & $3(30)$ & $1(9.1)$ \\
\hline & $36-40$ & $1(10)$ & $2(18.2)$ \\
\hline \multirow[t]{3}{*}{ Race } & White & $5(50)$ & $4(36.4)$ \\
\hline & Black & $1(10)$ & 0 \\
\hline & Brown & $4(40)$ & $7(63.6)$ \\
\hline \multirow[t]{4}{*}{ Marital status } & Married & $3(30)$ & $4(36.4)$ \\
\hline & $\begin{array}{l}\text { Single without } \\
\text { a partner }\end{array}$ & $1(10)$ & $1(9.1)$ \\
\hline & $\begin{array}{l}\text { Single with } \\
\text { a partner }\end{array}$ & $5(50)$ & $6(54.5)$ \\
\hline & Divorced & $1(10)$ & 0 \\
\hline \multirow{3}{*}{$\begin{array}{l}\text { Family income } \\
\text { (minimum wage) }\end{array}$} & 1 & $4(40)$ & $2(18.2)$ \\
\hline & 2 to 3 & $5(50)$ & $6(54.5)$ \\
\hline & Above 3 & $1(10)$ & $3(27.3)$ \\
\hline \multirow[t]{6}{*}{ Level of education } & $\begin{array}{l}\text { Less than primary } \\
\text { education }\end{array}$ & $1(10)$ & 0 \\
\hline & Primary education & $1(10)$ & $1(9.05)$ \\
\hline & $\begin{array}{l}\text { Lower secondary } \\
\text { education }\end{array}$ & $1(10)$ & $4(36.4)$ \\
\hline & $\begin{array}{l}\text { Upper secondary } \\
\text { education }\end{array}$ & $5(50)$ & $3(27.3)$ \\
\hline & $\begin{array}{l}\text { Incomplete tertiary } \\
\text { education }\end{array}$ & $1(10)$ & $2(18.2)$ \\
\hline & $\begin{array}{l}\text { Complete tertiary } \\
\text { education }\end{array}$ & $1(10)$ & $1(9.05)$ \\
\hline \multirow[t]{2}{*}{ Occupation } & Homemaker & $2(20)$ & $4(36.4)$ \\
\hline & Other & $8(80)$ & $7(63.6)$ \\
\hline \multirow[t]{3}{*}{ Physical activity } & Sedentary & $6(60)$ & $8(72.7)$ \\
\hline & Not very active & $4(40)$ & $1(9.1)$ \\
\hline & Active & 0 & $2(18.2)$ \\
\hline \multirow{4}{*}{$\begin{array}{l}\text { Frequency of leisure } \\
\text { activities }\end{array}$} & Once a week & $5(50)$ & $6(54.5)$ \\
\hline & Once a fortnight & $1(10)$ & $3(27.3)$ \\
\hline & Once a month & $3(30)$ & $1(9.1)$ \\
\hline & Rarely or never & $1(10)$ & $1(9.1)$ \\
\hline \multirow[t]{3}{*}{ Religion } & Catholic & $4(40)$ & $5(45.4)$ \\
\hline & Protestant & $6(60)$ & $4(36.4)$ \\
\hline & None & 0 & $2(18.2)$ \\
\hline \multirow[t]{5}{*}{ Pregnancy (no.) } & 1 & $3(30)$ & $4(36.4)$ \\
\hline & 2 & $3(30)$ & $6(54.5)$ \\
\hline & 3 & $2(20)$ & 0 \\
\hline & 4 & 0 & 0 \\
\hline & 5 & $2(20)$ & $1(9.1)$ \\
\hline Age band at first & $18-23$ & $8(80)$ & $7(63.6)$ \\
\hline
\end{tabular}

Table 1 Sociodemographic profile of the participants in this study (Continued)

\begin{tabular}{llll}
\hline $\begin{array}{l}\text { Sociodemographic } \\
\text { feature }\end{array}$ & $\begin{array}{l}\text { Music therapy } \\
\text { group n (\%) }\end{array}$ & $\begin{array}{l}\text { Control } \\
\text { group n (\%) }\end{array}$ \\
\hline pregnancy (years) & $24-29$ & $2(20)$ & $4(36.4)$ \\
& $30-35$ & $0(0)$ & $0(0)$ \\
Child (no.) & $36-40$ & $0(0)$ & $0(0)$ \\
& 1 & $7(70)$ & $6(54.5)$ \\
& 2 & $2(20)$ & $3(27.3)$ \\
Abortion & 3 & $1(10)$ & $1(9.1)$ \\
& 4 & 0 & $1(9.1)$ \\
& Yes & $6(60)$ & $4(36.4)$ \\
& No & $4(40)$ & $7(63.6)$ \\
\hline
\end{tabular}

emotions [24]. In fact, participants in MTG were able to express their feelings about their preterm infants or any other situations that were causing them distress or discontent. In other studies, music therapy sessions were intended to improve mother-baby relationship [11, 25, 26], with no specific concern for maternal health.

The present study demonstrated statistically significant improvements on both anxiety and depression scores in MTG. This finding confirmed our hypothesis that the use of music therapy can reduce the symptoms of anxiety and depression in mothers of preterm infants in the NICU. However, the improvement in depression raw scores did not necessarily have an impact on the level of depression as determined by BDI (minimum, mild, moderate, or severe).

Several other studies have shown improvement in depressive and anxious states as a result of music therapy interventions [18, 27]. The beneficial effects on the symptoms of anxiety and depression found in this study corroborate the neurophysiological basis of listening to familiar songs. Listening to pleasant music promotes emotional self-regulation [28] by increasing dopaminergic activity $[29,30]$ in the ventral striatum and ventral tegmental area and by decreasing the reactivity of the hypothalamic-pituitary-adrenal axis. In turn, these changes decrease serum cortisol levels [31], increase the synthesis and release of central and peripheral endocannabinoids such as anandamide and endorphins, and increase the predominance of parasympathetic heart modulation [32].

HRV results (SDNN, rMSSD, LF, and HF) in the first evaluation were not within the normal range [7] in the sample studied. Stress and anxiety related to having their children hospitalized, as well as the high degree of sedentarism of mothers in both groups (60\% in MTG and $72.7 \%$ in CG, Table 1) may justify these findings. 
Table 2 Psychological and cardiological outcomes in the initial and final evaluations

\begin{tabular}{|c|c|c|c|c|c|c|}
\hline \multirow[t]{2}{*}{ Parameter } & \multicolumn{3}{|l|}{ Music therapy group } & \multicolumn{3}{|l|}{ Control group } \\
\hline & Initial Mean \pm SD & Final Mean $\pm S D$ & Effect size & Initial Mean \pm SD & Final Mean $\pm S D$ & Effect size \\
\hline$\overline{\mathrm{BAl}}$ & $15.10 \pm 10.25$ & $5.40 \pm 4.72^{*}$ & $0.519(\mathrm{M})$ & $10.70 \pm 8.54$ & $6.00 \pm 4.94$ & $0.319(\mathrm{~S})$ \\
\hline $\mathrm{BDI}$ & $15.70 \pm 10.68$ & $6.30 \pm 5.52^{*}$ & $0.483(S)$ & $16.00 \pm 17.95$ & $10.20 \pm 16.26$ & $0.163(S)$ \\
\hline RR intervals & $718.80 \pm 101.73$ & $630.70 \pm 402.50$ & $0.148(S)$ & $770.53 \pm 121.14$ & $745.95 \pm 122.88$ & $0.100(\mathrm{~S})$ \\
\hline SDNN (ms) & $35.01 \pm 14.92$ & $44.53 \pm 12.95^{*} \#$ & $-0.322(\mathrm{~S})$ & $41.35 \pm 19.90$ & $43.53 \pm 22.11$ & $-0.051(S)$ \\
\hline RMSSD (ms) & $23.66 \pm 10.21$ & $36.59 \pm 17.58^{*}$ & $-0.410(S)$ & $28.14 \pm 15.82$ & $31.59 \pm 20.07$ & $-0.095(S)$ \\
\hline pNN50 (\%) & $6.08 \pm 7.96$ & $18.37 \pm 17.30^{*}$ & $-0.415(S)$ & $8.85 \pm 12.08$ & $11.54 \pm 17.96$ & $-0.087(\mathrm{~S})$ \\
\hline SD1 & $16.76 \pm 7.22$ & $25.91 \pm 12.45^{*}$ & $-0.410(S)$ & $18.41 \pm 12.68$ & $22.41 \pm 14.34$ & $-0.146(S)$ \\
\hline SD2 & $46.50 \pm 20.16$ & $56.95 \pm 15.63$ & $-0.278(S)$ & $51.75 \pm 30.35$ & $58.25 \pm 28.32$ & $-0.110(S)$ \\
\hline DFA a1 & $1.11 \pm 0.22$ & $1.05 \pm 0.35$ & $0.102(S)$ & $1.12 \pm 0.24$ & $1.16 \pm 0.23$ & $-0.084(\mathrm{~S})$ \\
\hline DFA a2 & $0.94 \pm 0.16$ & $0.89 \pm 0.24$ & $0.121(S)$ & $1.05 \pm 0.34$ & $0.86 \pm 0.21$ & $0.318(\mathrm{~S})$ \\
\hline VLF $(0-0.04 \mathrm{~Hz})$ & $733.50 \pm 774.68$ & $823.60 \pm 675.78$ & $-0.061(\mathrm{~S})$ & $1039.20 \pm 1026.09$ & $943.10 \pm 1432.13$ & $0.038(\mathrm{~S})$ \\
\hline LF $(0.04-0.15 \mathrm{~Hz})$ & $508.90 \pm 433.67$ & $630.70 \pm 402.50$ & $-0.144(S)$ & $504.50 \pm 419.49$ & $601.30 \pm 595.61$ & $-0.093(S)$ \\
\hline $\mathrm{HF}(0.15-0.4 \mathrm{~Hz})$ & $565.20 \pm 1013.54$ & $611.10 \pm 462.50$ & $-0.029(\mathrm{~S})$ & $397.30 \pm 331.67$ & $435.60 \pm 503.28$ & $-0.044(S)$ \\
\hline Total & $1808.00 \pm 1798.51$ & $1950.12 \pm 1364.49$ & $-0.044(\mathrm{~S})$ & $1941.20 \pm 1660.41$ & $1980.00 \pm 2200.50$ & $-0.009(S)$ \\
\hline $\mathrm{LF} / \mathrm{HF}$ & $1.95 \pm 1.14$ & $1.85 \pm 2.01$ & $0.030(S)$ & $2.20 \pm 2.23$ & $1.88 \pm 1.23$ & $0.088(\mathrm{~S})$ \\
\hline LF (n.u.) & $60.14 \pm 18.61$ & $53.35 \pm 21.43$ & $0.166(S)$ & $58.38 \pm 19.23$ & $60.13 \pm 14.35$ & $-0.051(\mathrm{~S})$ \\
\hline HF (n.u.) & $39.83 \pm 18.62$ & $46.65 \pm 21.45$ & $-0.167(S)$ & $41.60 \pm 19.26$ & $39.87 \pm 14.35$ & $0.050(\mathrm{~S})$ \\
\hline
\end{tabular}

SD Standard deviation, $B A$ I Beck Anxiety Inventory, BDI Beck Depression Inventory, RR intervals Intervals between consecutive heartbeats, SDNN Standard deviation of NN intervals, NN intervals Interbeat intervals from which artifacts have been removed, RMSSD Root mean square of successive differences between adjacent RR intervals, $p N N 50$, NN50 count divided by the total number of NN intervals, NN50 Number of successive NN intervals differing more than 50 ms, SD1 Instantaneous beat-to-beat variability, SD2 Continuous beat-to-beat variability, DFA a1 Detrended fluctuation analysis of short-term fractal scaling exponents, DFA a2 Detrended fluctuation analysis of long-term fractal scaling exponents, VLF Very low frequency, LF Low frequency, HF High frequency, (M) Medium effect size [20], (S) Small effect size [20]; ${ }^{*}$ significant at $p \leq 0.05$ in intergroup evaluation in the final evaluation using paired sample t-test or Wilcoxon test; \# significant at $p<0.05$ in intergroup evaluation in the final evaluation using t-test

Poincaré plot indices SD1 and SD2 indicated similar results, but this method has the advantages of easier calculation and lower stationarity dependence. Indeed, according to these results, SD1 was higher in participants in MTG after music therapy intervention. As demonstrated by our findings, time domain analysis and SD1, both reflecting parasympathetic modulation, mainly identified differences between individuals before and after music therapy intervention.

Music is known to provide a state of relaxation, leading to a reduction in cardiac function in rest periods due to the elevation of parasympathetic modulation [33]. This reduction generates better electrical stability of the heart by decreasing the heart rate, the force of contraction of the atrial muscle, the conduction velocity of cardiac impulse in the atrioventricular node, and the blood flow through the coronary vessels, as well as by increasing the delay between atrial and ventricular contractions. This state of rest keeps the heart muscle healthy and prevents wear and tear of the organ [34]. Therefore, music therapy provides better electrical stability of the heart.

Neuroanatomical findings point to a connection between descending projections of the lateral hypothalamus and the dorsal motor nucleus of the vagus nerve. The lateral hypothalamus is a limbic structure involved in processing positive emotions and motivation [35, 36]. Thus, it is possible to infer that positive emotions originated during the music therapy intervention in this study sensitized the lateral hypothalamus of the participants and, consequently, maximized the vagal action on the heart, contributing to increased parasympathetic modulation.

Table $3 \mathrm{BAI}$ and BDI scores in the initial and final evaluations

\begin{tabular}{|c|c|c|c|c|c|c|c|}
\hline \multirow[t]{2}{*}{ Scale } & \multirow[t]{2}{*}{ Score } & \multicolumn{3}{|c|}{ Music therapy group } & \multicolumn{3}{|c|}{ Control group } \\
\hline & & Initialn (\%) & $\begin{array}{l}\text { Final } \\
\text { n (\%) }\end{array}$ & $p$ & $\begin{array}{l}\text { Initial } \\
\mathrm{n}(\%)\end{array}$ & $\begin{array}{l}\text { Final } \\
\text { n (\%) }\end{array}$ & $p$ \\
\hline \multirow[t]{4}{*}{$\mathrm{BAl}$} & Minimum & $4(40)$ & $9(90)$ & $0.045^{*}$ & $7(63.6)$ & $9(81.8)$ & 0.522 \\
\hline & Light & $2(20)$ & $1(10)$ & & $2(18.2)$ & $2(18.2)$ & \\
\hline & Moderate & $4(40)$ & 0 & & $2(18.2)$ & 0 & \\
\hline & Serious & 0 & 0 & & 0 & 0 & \\
\hline \multirow[t]{4}{*}{$\mathrm{BDI}$} & Minimum & $4(40)$ & $7(70)$ & 0.150 & $6(54.5)$ & $8(72.7)$ & 0.747 \\
\hline & Light & $2(20)$ & $3(30)$ & & $2(18.2)$ & $2(18.2)$ & \\
\hline & Moderate & $4(40)$ & 0 & & $2(18.2)$ & 0 & \\
\hline & Serious & 0 & 0 & & $1(9.1)$ & 0 & \\
\hline
\end{tabular}

BAl Beck Anxiety Inventory, BDI Beck Depression Inventory; * significant at $p \leq$ 0.05 using Fisher's exact test 


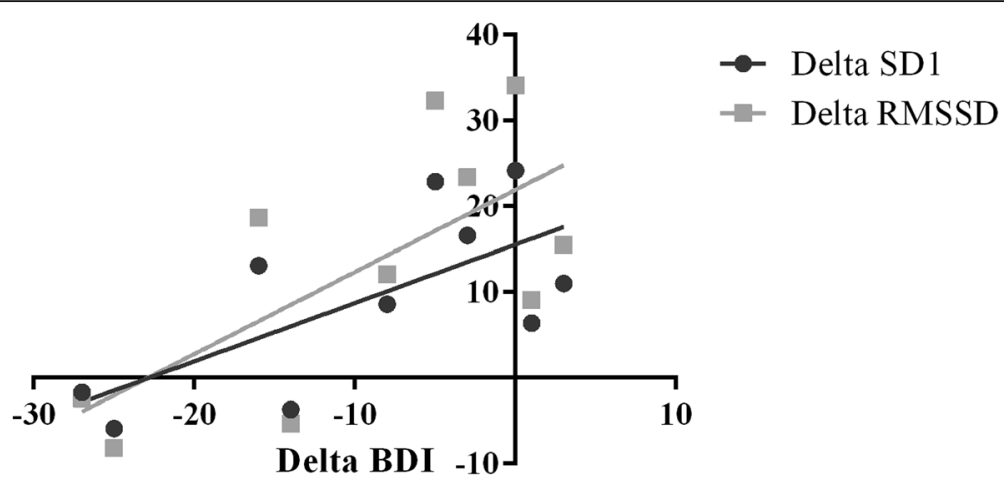

Fig. 2 Correlation between the deltas of the Beck Depression Inventory results and the deltas of the heart rate variability indices (RMSSD and SD1). BDI: Beck Depression Inventory; SD1: instantaneous beat-to-beat variability; RMSSD: root mean square of successive differences between adjacent RR intervals (ms).

Another factor that supports the predominance of parasympathetic modulation is that listening to familiar songs can stimulate the central and peripheral production and release of nitric oxide (NO) [32, 35]. Among the many other biological roles played by $\mathrm{NO}$, it acts on the peripheral vasomotor tone, characterized by vasodilation and reduction of blood pressure values. For this reason, the action of $\mathrm{NO}$ on the cardiovascular system is one of the ways to explain the parasympathetic predominance of cardiac autonomic modulation after music therapy intervention.

The cardiovascular system is also sensitive to a wide variety of psychological and behavioral states. In this regard, a decrease in the release of catecholamines (adrenaline and noradrenaline) due to musical stimuli could explain the regulation of cardiovascular variables [37]. In addition, parasympathetic activity predominates during relaxation [38]. Taking into account the decrease in anxiety and depression symptoms after music therapy sessions, it can be inferred that the increase in parasympathetic activity is associated with a positive emotional state. Such inference can be corroborated by the correlation found between depression and HRV indices (SD1 and RMSSD).

The vagus nerve, one of the main elements of the parasympathetic portion of the ANS, represents an important afferent component that directly connects the regions of the brain associated with emotions such as the hypothalamus and amygdala [39], and also controls the concentration of neurotransmitters [40]. Vagal stimulation has been studied for the treatment of depressive disorders $[40,41]$. Thus, it is possible that music therapy benefitted the participants in many different ways (anxiety, depression, and cardiovascular aspects) due to the interactions between neurotransmitters and ANS.

In a study population consisting of subjects in good general health, the effects of improvisational music therapy on HRV were evaluated at three different moments, totalling $90 \mathrm{~min}$ : $30 \mathrm{~min}$ before the music therapy session, 30 min during the session, and $30 \mathrm{~min}$ after the session. The deviation of the RR intervals was similar before the beginning and after the end of the music therapy session [42]. Corroborating this outcome, in the present study, no differences were observed between the initial and final evaluations of RR intervals in either group.

In the one hand, in a randomized study using receptive music therapy [43], the same method applied in the present study, HRV was assessed during musical listening, and a significant increase in RR intervals was observed. On the other hand, in our study, this was not found. Therefore, based on this discrepancy of results and due to the scarcity of reference materials, we suggest new studies with a greater number of subjects, as proposed in the initial sample calculation, and HRV evaluation during and after music therapy sessions.

In many studies, HRV has been evaluated under resting or post-exercise recovery conditions, and in most previous studies involving music this parameter has been verified during musical listening [42, 44]. The novelty of the method used in the present research lies in the fact that the final HRV was analyzed at least $12 \mathrm{~h}$ after music therapy sessions were concluded, thus allowing us to verify non-immediate benefits of music listening. Given this time lapse, the benefits of music therapy on HRV seem to be prolonged.

Having lost almost $46 \%$ of the sample for several reasons was a major setback for our study. Another limitation was the collection of HRV only during rest and not both under rest and under stress, although the former has been well documented in the literature. It is also worth noting the impossibility of carrying out a neuroendocrine evaluation (cortisol and catecholamines) of the participants to confirm the autonomic findings, since the appropriate control of their diet was not feasible in a hospital setting. 
We hope that our results stimulate future studies that corroborate the influence of music therapy on the physical and emotional well-being of mothers whose preterm infants are in the NICU. It would also be important to conduct studies encompassing other types of population aiming to evaluate the potential of music therapy for cardiac rehabilitation and psychophysiological improvement.

\section{Conclusion}

Anxiety, depression, and HRV were analyzed in mothers of preterms admitted to the NICU before and after music therapy sessions to evaluate the effects of this type of intervention. To our knowledge, no similar studies have been conducted. Parasympathetic activity increased after music therapy sessions, which suggests that music listening can reduce anxiety and depression under the conditions tested. Therefore, it can be considered a reliable and low-cost therapy to be adopted by public health systems. The effect of music therapy on cardiac autonomic modulation provides preliminary clinical evidence of its use as a strategy for cardiovascular disease prevention.

\begin{abstract}
Abbreviations
ANS: Autonomic nervous system; BAl: Beck anxiety inventory; BDI: Beck depression inventory; bpm: Beats per minute; CG: Control group; HF: High frequency; HRV: Heart rate variability; LF: Low frequency; MTG: Music therapy group; NICU: Neonatal intensive care unit; NN intervals: Interbeat intervals from which artifacts have been removed; NN50: Number of successive NN intervals differing more than 50 ms; NO: Nitric oxide; pNN50: NN50 count divided by the total number of NN intervals; RMSSD: Root mean square of successive differences between adjacent RR intervals:" RR intervals: Intervals between consecutive heartbeats; SD1: Instantaneous beat-to-beat variability; SD2: Continuous beat-to-beat variability; SDNN: Standard deviation of NN intervals; VLF: Very low frequency; WHMDI: Women's Hospital and Maternity
\end{abstract} Dona Iris.

\section{Acknowledgments \\ The authors are deeply grateful to psychologist Lilian Arrais for her collaboration during the application of the Beck Anxiety Inventory and Beck Depression Inventory and to Suzana Oellers for the important contributions during the process of revising this manuscript and the English language editing.}

\section{Funding}

This work was supported by Conselho Nacional de Desenvolvimento Científico e Tecnológico (CNPq, \# 441982/2014) and Fundação de Amparo à Pesquisa do Estado de Goiás (FAPEG, Chamada 3/2016). The funding bodies did not play any roles in the design of the study, data collection, analysis, data interpretation, or writing of the manuscript.

\section{Availability of data and materials}

The datasets used and/or analyzed during the current study are available from the corresponding author on reasonable request.

\section{Authors' contributions}

MKAR, TRMAS, and TCP developed the study concept and designed both the research and the intervention; JCMO and JBRD contacted the mothers, got their consents, and collected heart rate variability data; GRP, KS, and RBS conducted the research. ACSR analyzed the data and drafted the manuscript; GRP, KS, and ACSR provided critical revisions. All authors read and approved the final manuscript.

\section{Ethics approval and consent to participate}

The research project was approved by the WHMDI Academic Board and by the Ethics and Research Committee of the Universidade Federal de Goiás (no. 636368). It was registered in the Brazilian Registry of Clinical Trials (no. RBR-3×7gz8) and endorses the rules of the Committee on Publication Ethics. All participants provided written informed consent.

\section{Consent for publication}

Not applicable.

\section{Competing interests}

The authors declare that they have no competing interests.

\section{Publisher's Note}

Springer Nature remains neutral with regard to jurisdictional claims in published maps and institutional affiliations.

\section{Author details}

${ }^{1}$ School of Medicine, Universidade Federal de Goiás, Goiânia, GO, Brazil. ${ }^{2}$ School of Music and Performing Arts, Universidade Federal de Goiás, Goiânia, GO, Brazil. ${ }^{3}$ Center of Neuroscience and Cardiovascular Research, Universidade Federal de Goiás, Goiânia, GO, Brazil. ${ }^{4}$ Department of Morphology, Biological Sciences Institute, Universidade Federal de Goiás, Goiânia, GO, Brazil.

Received: 15 June 2018 Accepted: 21 November 2018 Published online: 13 December 2018

\section{References}

1. Alexopoulou P, Evagelou E, Mpakoula-Tzoumaka C, Kyritsi-Koukoulari E. Assessing anxiety and depression in parents of preterm infants. J Neonatal Nurs. 2018;24:273-6 https://doi.org/10.1016/j.jnn.2018.05.009.

2. Perry SE, Hockenberry MJ, Lowdermilk DL, Wilson D. Maternal child nursing care. 5th ed. St. Louis: Elsevier Health Sciences; 2013.

3. Bhat SK, Beilin LJ, Robinson M, Burrows S, Mori TA. Relationships between depression and anxiety symptoms scores and blood pressure in young adults. J Hypertens. 2017;35:1983-91. https://doi.org/10.1097/HJH. 0000000000001410.

4. Carney RM, Freedland KE, Stein PK, Miller GE, Steinmeyer B, Rich MW, et al. Heart rate variability and markers of inflammation and coagulation in depressed patients with coronary heart disease. J Psychosom Res. 2007;62: 463-7. https://doi.org/10.1016/j.jpsychores.2006.12.004.

5. Munakata M, Ichii S, Nunokawa T, Saito Y, Ito N, Fukudo S, et al. Influence of night shift work on psychologic state and cardiovascular and neuroendocrine responses in healthy nurses. Hypertens Res. 2001;24:25-31. https://doi.org/10.1291/hypres.24.25.

6. Pumprla J, Howorka K, Groves D, Chester M, Nolan J. Functional assessment of heart rate variability: physiological basis and practical applications. Int J Cardiol. 2002;84:1-14. https://doi.org/10.1016/S0167-5273(02)00057-8.

7. Task Force of the European Society of Cardiology and the North American Society of Pacing Electrophysiology. Heart rate variability: standards of measurement, physiological interpretation, and clinical use. Circulation. 1996;93:1043-65.

8. Vanderlei LCM, Pastre CM, Hoshi RA, Carvalho TD, Godoy MF. Noções básicas de variabilidade da frequência cardíaca e sua aplicabilidade clínica. Rev Bras Cir Cardiovasc. 2009;24:205-17. https://doi.org/10.1590/S010276382009000200018

9. Bruscia KE. Definindo musicoterapia. 3rd ed. Dallas: Barcelona Publishers; 2016.

10. Dileo C, Bradt J. Medical music therapy: a meta-analysis and agenda for future research. Cherry Hill: Jeffrey Books; 2005

11. Schlez A, Litmanovitz I, Bauer S, Dolfin T, Regev R, Arnon S. Combining kangaroo care and live harp music therapy in the neonatal intensive care unit setting. Isr Med Assoc J. 2011;13:354-8.

12. Arnon S, Diamant C, Bauer S, Regev R, Sirota G, Litmanovitz I. Maternal singing during kangaroo care led to autonomic stability in preterm infants and reduced maternal anxiety. Acta Paediatr. 2014;103:1039-44. https://doi. org/10.1111/apa.12744.

13. Arnon S. Intervenção musicoterápica no ambiente da unidade de terapia intensiva neonatai. J Pediatr. 2011;87:183-5. https://doi.org/10. 2223/JPED.2091 
14. Cunha JA. Manual da versão em português das Escalas Beck. São Paulo: Casa do Psicólogo; 2001.

15. Giles DA, Draper N. Heart rate variability during exercise: a comparison of artefact correction methods. J Strength Cond Res. 2018;32:726-35.

16. Ribeiro JP, Moraes Filho RS. Variabilidade da freqüência cardíaca como instrumento de investigação do sistema nervoso autônomo. Rev Bras Hipertens. 2005;12:14-20.

17. Godoy MF. Nonlinear analysis of heart rate variability: a comprehensive review. J Cardiol Ther. 2016;3:528-33. https://doi.org/10.17554/j.issn.23096861.2016.03.101-4.

18. TRM A-S. Estudo randomizado testando musicoterapia na redução da fadiga relacionada ao câncer em mulheres com neoplasia maligna de mama ou ginecológica em curso de radioterapia. PhD [thesis]. Goiânia: Universidade Federal de Goiás; 2012

19. Poulsen MJ, Coto J. Nursing music protocol and postoperative pain. Pain Manag Nurs. 2018;19:172-6. https://doi.org/10.1016/j.pmn.2017.09.003.

20. Cohen J. Statistical power analysis for the behavioral sciences. 2nd ed Hillsdale: Lawrence Erlbaum Associates; 1988.

21. Carvalho AEV, Linhares MBM, Padovani FHP, Martinez FE. Anxiety and depression in mothers of preterm infants and psychological intervention during hospitalization in neonatal ICU. Span J Psychol. 2009;12:161-70. https://doi.org/10.1017/S1138741600001578.

22. Jasemi M, Aazami S, Zabihi RE. The effects of music therapy on anxiety and depression of cancer patients. Indian J Palliat Care. 2016;22:455-8. https:// doi.org/10.4103/0973-1075.191823.

23. Bieleninik $九$, Ghetti C, Gold C. Music therapy for preterm infants and their parents: a meta-analysis. Pediatrics. 2016;138:e20160971. https://doi.org/10. 1542/peds.2016-0971.

24. Dassa A, Amir D. The role of singing familiar songs in encouraging conversation among people with middle to late stage Alzheimer's disease. J Music Ther. 2014;51:131-53. https://doi.org/10.1093/jmt/thu007.

25. Ettenberger M, Cárdenas CR, Parker M, Odell-Miller H. Family-centred music therapy with preterm infants and their parents in the neonatal intensive care unit (NICU) in Colombia - a mixed-methods study. Nord J Music Ther. 2017;26:207-34. https://doi.org/10.1080/08098131.2016.1205650.

26. Vianna MNS, Barbosa AP, Carvalhaes AS, Cunha AJLA. A musicoterapia pode aumentar os índices de aleitamento materno entre mães de recémnascidos prematuros: Um ensaio clínico randomizado controlado. J Pediatr. 2011;87:206-12. https://doi.org/10.1590/S0021-75572011000300005.

27. Aalbers S, Fusar-Poli L, Freeman RE, Spreen M, Ket JCF, Vink AC, et al. Music therapy for depression. Cochrane Database Syst Rev. 2017;11:CD004517. https://doi.org/10.1002/14651858.CD004517.pub3.

28. Erkkilä J, Punkanen M, Fachner J, Ala-Ruona E, Pöntiö I, Tervaniemi M, et al. Individual music therapy for depression: randomised controlled trial. $\mathrm{Br}$ J Psychiatry. 2011;199:132-9. https://doi.org/10.1192/bjp.bp.110.085431.

29. Boso M, Politi P, Barale F, Emanuele E. Neurophysiology and neurobiology of the musical experience. Funct Neurol. 2006;21:187-91.

30. Menon $V$, Levitin DJ. The rewards of music listening: response and physiological connectivity of the mesolimbic system. Neurolmage. 2005;28: 175-84. https://doi.org/10.1016/j.neuroimage.2005.05.053.

31. Koelsch S, Fuermetz J, Sack U, Bauer K, Hohenadel M, Wiegel M, et al. Effects of music listening on cortisol levels and propofol consumption during spinal anesthesia. Front Psychol. 2011;2:58. https://doi.org/10.3389/fpsyg. 2011.00058.

32. Deljanin-llic M, Kocic G, Lazarevic G, Pavlovic R, Simonovic D. Effects of music therapy on endothelial function in patients with coronary artery disease participating in aerobic exercise therapy. Altern Ther Heal Med. 2017;23.

33. Chuang CY, Han WR, Li PC, Young ST. Effects of music therapy on subjective sensations and heart rate variability in treated cancer survivors: a pilot study. Complement Ther Med. 2010;18:224-6. https:// doi.org/10.1016/j.ctim.2010.08.003.

34. Vale AF, Ribeiro MKA, Nogueira YL, Silva TRA, Gomes MBF, Simões K, et al. A systematic review of cardiac autonomic modulation in mothers and their infants. Jacobs J Pediatr. 2015;1:009

35. Salamon E, Kim M, Beaulieu J, Stefano GB. Sound therapy induced relaxation: down regulating stress processes and pathologies. Med Sci Monit. 2003;9:RA116-21.

36. Hosoya Y, Matsushita M. Brainstem projections from the lateral hypothalamic area in the rat, as studied with autoradiography. Neurosci Lett. 1981;24:111-6. https://doi.org/10.1016/0304-3940(81)90232-9.
37. Shepherd JT. Franz Volhard lecture. Increased systemic vascular resistance and primary hypertension: the expanding complexity. J Hypertens. 1990;8: S15-27.

38. Kleiger RE, Stein PK, Bigger JT Jr. Heart rate variability: measurement and clinical utility. Ann Noninvasive Electrocardiol. 2005;10:88-101. https://doi. org/10.1111/j.1542-474X.2005.10101.x.

39. Esperidião-Antonio V, Majeski-Colombo M, Toledo-Monteverde D, MoraesMartins G, Fernandes JJ, Bauchiglioni de Assis M, et al. Neurobiology of emotions: an update. Int Rev Psychiatry. 2017;29:293-307. https://doi.org/10. 1080/09540261.2017.1285983.

40. Carpenter LL, Moreno FA, Kling MA, Anderson GM, Regenold WT, Labiner DM, et al. Effect of vagus nerve stimulation on cerebrospinal fluid monoamine metabolites, norepinephrine, and gamma-aminobutyric acid concentrations in depressed patients. Biol Psychiatry. 2004;56:418-26. https://doi.org/10.1016/j.biopsych.2004.06.025

41. Rush AJ, Marangell LB, Sackeim HA, George MS, Brannan SK, Davis SM, et al. Vagus nerve stimulation for treatment-resistant depression: a randomized, controlled acute phase trial. Biol Psychiatry. 2005;58:347-54. https://doi.org/ 10.1016/j.biopsych.2005.05.025.

42. Raglio A, Oasi O, Gianotti M, Bellandi D, Manzoni V, Goulene K, et al. Music therapy, emotions and the heart: a pilot study. G Ital Med Lav Ergon. 2012; 34:438-43.

43. Chiu HW, Lin LS, Kuo MC, Chiang HS, Hsu CY. Using heart rate variability analysis to assess the effect of music therapy on anxiety reduction of patients. Comput Cardiol. 2003;30:469-72.

44. Kachanathu SJ, Verma SK, Khanna GL. Effect of music therapy on heart rate variability: a reliable marker to pre-competition stress in sports performance. J Med Sci. 2013;13:418-24. https://doi.org/10.3923/jms.2013.418.424.

\section{Ready to submit your research? Choose BMC and benefit from:}

- fast, convenient online submission

- thorough peer review by experienced researchers in your field

- rapid publication on acceptance

- support for research data, including large and complex data types

- gold Open Access which fosters wider collaboration and increased citations

- maximum visibility for your research: over 100M website views per year

At BMC, research is always in progress.

Learn more biomedcentral.com/submissions 